\title{
Congenital Zika Virus Infection: a Review with Emphasis on the Spectrum of Brain Abnormalities
}

\author{
Leão VHP ${ }^{1} \cdot$ MM Aragão $^{1} \cdot$ RS Pinho $^{1} \cdot$ AN Hazin $^{2} \cdot$ AR Paciorkowski $^{3} \cdot$ AC Penalva de Oliveira $^{4}$. \\ Marcelo Rodrigues Masruha ${ }^{1,5}$
}

Published online: 3 September 2020

(C) Springer Science+Business Media, LLC, part of Springer Nature 2020

\begin{abstract}
Purpose of Review In 2016, the World Health Organization declared the Zika virus (ZIKV) outbreak a Public Health Emergency of International Concern following a cluster of associated neurological disorders and neonatal malformations. Our aim is to review the clinical and neuroimaging findings seen in congenital Zika syndrome.

Recent Findings ZIKV injures neural progenitor cells in the hippocampus, a brain region important for learning, memory, cognition, and emotion/stress response. Positron emission tomography has revealed global neuroinflammation in ZIKV infection in animal models.

Summary Congenital Zika syndrome is associated with a spectrum of brain abnormalities, including microcephaly, parenchymal calcifications, malformations of cortical development and defective neuronal migration, corpus callosum abnormalities, ventriculomegaly, and brainstem and cerebellar abnormalities.
\end{abstract}

Keywords Zika virus $\cdot$ Zika virus infection $\cdot$ Microcephaly $\cdot$ Neuroimaging

\section{Introduction}

Zika virus (ZIKV) is a positive-sense single-stranded RNA virus belonging to the Flaviviridae family [1]. It was first isolated in 1947 from the serum of a sentinel Rhesus monkey in the Zika forest of Uganda [2]. In 2007, the virus emerged in the Federated States of Micronesia and affected approximately $75 \%$ of the population (approximately 5000 infections) within a few months [3]. During the first 60 years of its known

This article is part of the Topical Collection on Pediatric Neurology

Marcelo Rodrigues Masruha

marcelomasruha@gmail.com

1 Department of Neurology and Neurosurgery, Escola Paulista de Medicina, São Paulo, Brazil

2 Department of Radiology, Instituto de Medicina Integral Professor Fernando Figueira, Recife, Brazil

3 Departments of Neurology, Pediatrics, Biomedical Genetics, and Neuroscience, University of Rochester Medical Center, Rochester, NY, USA

4 Instituto de Infectologia Emílio Ribas, São Paulo, Brazil

5 Instituto de Neurociência do Espírito Santo, Fausto Vincenzo Tancredi Street, 86, Vitória, ES 29050-270, Brazil existence, fewer than 20 human infections were recorded [4]. In November 2016, the transmission of ZIKV spread to over 48 countries [5].

\section{Transmission}

ZIKV is transmitted primarily by the Aedes mosquito species, especially by Aedes aegypti and Aedes albopictus, but can also be transmitted from human to human through blood transfusions, sexual intercourse, and during pregnancy [6]. Vertical transmission occurs presumably through the placenta, although can also occur through breast milk or by a bloodborne route [7]. The risk of developing congenital Zika Syndrome (CZS) is increased when the infection occurs in the first trimester [8].

\section{Definition of Congenital Zika Syndrome}

CZS results from vertical transmission of ZIKV from an infected woman to the fetus during pregnancy [7]. Although many of the signs and symptoms of this syndrome are shared by other congenital infections, five features differentiate CZS from other congenital infections: (1) severe microcephaly with partially collapsed skull, (2) thin cerebral cortices with 
subcortical calcifications, (3) macular scarring and focal pigmentary retinal mottling, (4) congenital contractures, and (5) marked early hypertonia [9].

Suspected cases of CZS can be classified, based on neuroimaging and laboratory results for ZIKV and other relevant infections. Definite cases are those with laboratory evidence of ZIKV infection. Probable cases present with characteristic neuroimaging findings without laboratory evidence of ZIKV infection, but negative laboratory results for other congenital infections [10].

\section{Possible Explanations for the Outbreak of ZIKV}

A single serine-to-asparagine substitution in the viral polyprotein substantially increased ZIKV infectivity. Evolutionary analysis indicates that this sequence variation occurred just before the outbreak in French Polynesia and has been maintained during subsequent spread to the Americas [11]. The outbreak of ZIKV can also be explained based on the structural similarity between ZIKV and dengue viruses. The antibodies produced against these flaviviruses can cross-react without neutralization of the virus and can also enhance ZIKV infection [12], a process known as antibodydependent enhancement [13].

In addition to previous explanations for the outbreak of ZIKV listed above, ZIKV infection of the vector A. aegypti can also cause neuroexcitation in mosquitoes, that could contribute to increased diurnal locomotion activity compared with uninfected females, increasing the chances of transmission to new susceptible hosts [14].

\section{Decline in ZIKV Incidence}

In 2017, there was a marked decline in reported ZIKV cases and its severe disease manifestations [15]. In addition, there has also been a relevant decline in the incidence of dengue and chikungunya cases in Brazil, suggesting a possible role for climatic and other factors affecting mosquito density or cross-immunity between arboviruses [16].

\section{Neuropathology}

\section{Pathogenesis}

The microcephaly and structural brain abnormalities associated with CZS are the consequences of in utero destruction of neural progenitor cells and persistent inflammatory responseassociated molecules [5]. It is also known that ZIKV infection suppresses cranial osteogenesis, which can be associated with craniofacial bone malformations. Combined with neural progenitor cell loss and the resulting microcephaly, these can account for the cardinal features of ZIKV-mediated birth defects [17].

\section{Neurotropism and Histopathological Findings}

The spectrum of histopathological findings can be summarized as follows: (1) malformations of cortical development, represented by abnormal bands of germinal matrix towards the cortex, meningeal glioneuronal heterotopias, polymicrogyria, and cortical dysplasia; (2) destructive lesions with neuronal degeneration, apoptosis, and coarse and filamentous calcification; (3) inflammation with predominance of T lymphocytes CD8+; and (4) hypoplastic lesions characterized by lack of descending fibers leading to hypoplasia of the pons, pyramids, and spinal corticospinal tracts [18]. In ZIKV-infected mice, positron emission tomography (PET) imaging revealed global neuroinflammation affecting the whole brain [19].

\section{Concerns About Persistence of the Virus in Blood and Tissues}

Viral persistence in the maternal blood seems to be associated with a failure of antiviral immunological clearance or the consequence of maternal reseeding from fetal infection [20]. In an autopsy of a 5-month infant with CZS, ZIKV RNA was detected in the brain, indicating viral persistence after a first trimester of gestation infection [21]. The transmission of ZIKV by breastfeeding can be the cause of postnatal microcephaly in previously healthy infants [22]. Infants born to mothers exposed to ZIKV during pregnancy showed progression of developmental, motor, and neurologic abnormalities even if they were born asymptomatic [23]. ZIKV exposure in the adult brain could have an effect on long-term memory or an increased risk for depression [24].

\section{Clinical Spectrum of Disease}

\section{Adult Features (Including Symptoms During Pregnancy)}

ZIKV infection has a self-limited course and $80 \%$ of the infected patients are asymptomatic [25]. The most frequent symptoms are conjunctivitis, mild fever, headache, skin rash, and diarrhea [5]. Autoimmune disorders caused by ZIKV can also occur in adults, including Guillain-Barré syndrome (GBS), transverse myelitis, and acute meningoencephalitis [26]. Stroke is also a complication from ZIKV vasculitis [27]. 


\section{Clinical Features of Congenital Zika Syndrome}

Children affected by CZS may develop severe symptoms, including often moderate to severe global neurodevelopmental delay, epilepsy, blindness, hearing loss, and hypotonia [28]. Among 48 infants with CZS, 85.4\% had irritability, becoming the most common described symptom, followed by upper motor neuron/extrapyramidal manifestations $(56.3 \%)$, epileptic seizures $(50 \%)$, and dysphagia (14.6\%) [29•]. Additionally, the nature of muscle tone abnormalities can change over time (e.g., hypotonia develops into spasticity) [30]. Extrapyramidal findings were predominantly characterized as dyskinesia and dystonias [31]. Prominent contractures of at least one joint were present in approximately $42 \%$ of cases, although arthrogryposis multiplex congenita was seen only in $10 \%$ of cases [32].

In patients with epilepsy, the main seizure types included infantile spasms ( $72 \%$ of the infants), focal motor seizures $(21 \%)$, and tonic seizures (4\%). The main electroencephalographic patterns were focal epileptiform discharges (51\%), multifocal epileptiform discharges (44\%), hypsarrhythmia (11\%), and burst-suppression (8\%) [33]. Microcephaly was present in $69 \%$ of children diagnosed with CZS. In these children, $67 \%$ were diagnosed with microcephaly at birth and $33 \%$ developed postnatal microcephaly, mainly during the first year of life. Time of diagnosis is also variable, with $46 \%$ of infants diagnosed at birth and $54 \%$ within 10 months of life [23].

Among infants with congenital ZIKV infection, there is a group of children with normal head circumference at birth who develop progressive microcephaly during the first year of life [34]. Even in the absence of abnormalities identified by prenatal and postnatal testing, the potential for long-term neurocognitive deficits remains [35-39].

Hyperactivity, severe irritability, and self-injurious behaviors have also been reported in infants with CZS [29•].

\section{Complementary Investigation of ZIKV Infection and CZS}

\section{Laboratory Methods}

Pregnant women with possible ZIKV exposure, who have a fetus with prenatal ultrasound findings consistent with CZS, should be tested by nucleic acid amplification test (NAAT) and IgM levels in maternal serum and NAAT in maternal urine. Consideration of amniocentesis should be individualized because data about its usefulness in diagnosing congenital ZIKV infection are limited [40]. Confirmation of an in utero infection can be made through a positive RTPCR in cord blood, neonatal blood, urine, placenta, or cerebrospinal fluid (CSF), as well as by the presence of specific IgM [41].

\section{Neuroimaging Findings}

\section{General Aspects}

The reported risk of fetal/infant abnormalities with maternal ZIKV infection ranges between 1 and 29\% [42]. The most prevalent brain congenital defects reported are the following: calcifications at the cortical-subcortical junction (Fig. 1a, b) (92.9\%); basal ganglia calcification (Fig. 1c) (57\%); periventricular calcifications (29.5\%); ventriculomegaly (Fig. 1d, e, g, i, j, k, l) (63.1\%); cerebellar abnormalities (Fig. 1d, j, k, 1) (47.9\%); corpus callosum abnormalities (Fig. 1d, g, h, 1) (46.2\%); and microcephaly (39.7\%) (Fig. 1d), almost $100 \%$ when the infection occurs in the first trimester of pregnancy $\left[43^{\bullet}\right]$.

\section{Brain Calcifications}

Brain calcifications are common in CZS, occurring in 88$100 \%$ of patients [44], especially involving the gray-white matter junction (Fig. 1a, b) [45]. Calcifications were also identified in basal ganglia (Fig. 1c), thalamus, cortex, and periventricular regions. In patients with periventricular calcifications (Fig. 1i), these were associated with areas of parenchymal thinning [46•].

Cortical-subcortical calcifications were located mainly in the frontal (Fig. 1a, b) (100\%) and parietal (68.7\%) lobes, and less frequently in the occipital $(50 \%)$ and temporal (43.7\%) lobes. Brain calcifications described in CZS can also be punctate and coarse (Fig. 1a, b) [47]. In some cases, a layered calcification appearance can be seen in cortical gray and white matter [48•].

\section{Microcephaly}

The definition of microcephaly varies from fetus to child [49]. It is defined as a fetal or newborn head circumference (HC) below the third percentile or, at least, two standard deviations (SDs) below the mean for sex, age, and ethnicity [50]. Severe microcephaly is defined as a $\mathrm{HC}$ below the parameters mentioned above [51]. Microcephaly is present in $39.7 \%$ of infants and, when the infection occurs in the first trimester, in almost $100 \%$ of affected individuals [43*]. Among microcephalic infants, severe microcephaly is identified in $54.9 \%$ of them $[52 \bullet \bullet]$.

As consequence to microcephaly, redundant skin of the scalp has been described in $67.4 \%$ of infants. Redundant skin could be best demonstrated by manually creating folds in the scalp and is evident in the forehead (37.3\%) or in the occipital and nuchal regions (Fig. 1d) (47\%) [32]. Skin redundancy is best explained by the collapse of the skull, which previously had larger dimensions. The latter can be the result of the decreased brain size or the suppressed cranial osteogenesis 
Fig. 1 Brain images of infants diagnosed with CZS. CT scan slices: images $\mathbf{a}, \mathbf{c}, \mathbf{i}, \mathbf{j}$, and $\mathbf{k}$. MRI images: $\mathbf{b}, \mathbf{d}, \mathbf{e}, \mathbf{f}, \mathbf{g}, \mathbf{h}, \mathbf{k}$, and l. a (CT) and b (MRI): coarse and punctate calcifications at the cortico-subcortical junction, predominating in the frontal lobes. c: basal ganglia calcifications. d: marked microcephaly with redundant scalp skin in the occipital region. e: marked dilatation of supratentorial ventricular system, simplified gyral pattern of the brain, and prominence of the subarachnoid space in the frontal regions. f: malformations of cortical development compatible with polymicrogyria in the frontal lobes with sparing of posterior cortical areas. g: thin/hypoplastic corpus callosum. h: short corpus callosum with dysgenetic aspect. i and $\mathbf{j}$ : tetraventricular dilatation, simplified gyral pattern of the brain, cerebellar and pons hypoplasia, and corticosubcortical and periventricular calcifications. k: asymmetric cerebellar hypoplasia with greater involvement of the right hemisphere, marked dilatation of the lateral ventricles with thinning of cerebral mantle, and prominence of cisterna magna. $\mathbf{l}$ : severe cerebellar hypoplasia

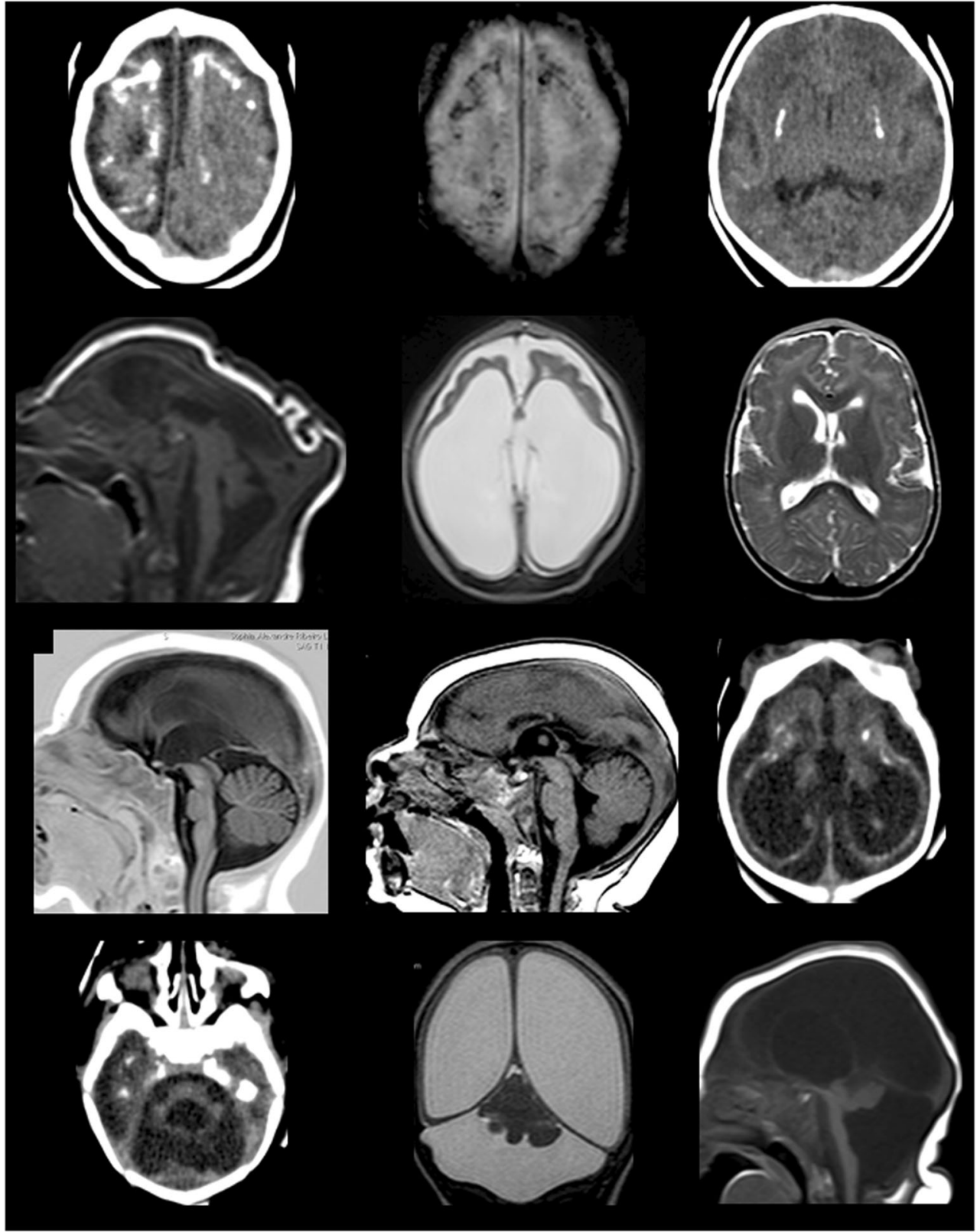

caused by ZIKV [17, 44]. Periorbital fullness, epicanthal folds, and mild retrognathia are the main facial features of these infants [32].

\section{Malformations of Cortical Development}

Malformations of cortical development were present in $89 \%$ of the cases, most frequently affecting the frontal lobes. Among them, lissencephaly-pachygyria spectrum and other focal migrational/post migrational abnormalities were the most frequent findings [53]. Other observed abnormalities included areas of polymicrogyria (Fig. 1f) accompanied by gyral simplification (Fig. 1d, e, g, i, k, 1) [54]. These abnormalities are usually asymmetric. Overall, the sulci were less prominent and widening of the sylvian and interhemispheric fissures was also found in neonates, as well as abnormal myelination [46•]. Gray matter heterotopia is rare [44].

Associated with the frequent finding of malformations of cortical development, infants with CZS have large reductions in parenchymal volume. In some cases, this is accompanied by enlargement of the subarachnoid spaces (Fig. 1e, i) [54-57]. Ventriculomegaly (Fig. 1d, e, g, i, j, k, l) occurs in $63 \%$ of patients with CZS [43•].

\section{Corpus Callosum Abnormalities}

Corpus callosum abnormalities are a common finding in CZS and occur in about $46 \%$ of cases [43•]. Typically, there is a 
thin, hypoplastic (Fig. 1d, g, 1), dysmorphic (Fig. 1h), or absent corpus callosum. Formation of the corpus callosum occurs between 8 and 20 weeks of gestational age [55, 58], suggesting that at least in some cases the insult to CNS morphology occurs concurrent with corpus callosum development.

\section{Hydrocephalus}

Among infants with CZS, approximately $18 \%$ had progressive ventriculomegaly and $5 \%$ had communicating hydrocephalus associated with increased frequency of seizures and worsening neurological impairment [59]. Hydrocephalus occurred without remarkable increase in the head circumference, and $92 \%$ of these children remained microcephalic [60].

\section{Posterior Fossa Abnormalities}

Cerebellar and brainstem hypoplasia (Fig. 1d, j, k, 1) were present, respectively in $24 \%$ and $20 \%$ of these infants [52, 61]. The cerebellar hemispheres usually had symmetric involvement, although asymmetric unilateral cerebellar hypoplasia (Fig. 1k) has been reported. The brainstem hypoplasia frequently involved the pons (Fig. 1d, g, j, l) [58••]. Brainstem and cerebellar calcifications occurred, respectively in $9.9 \%$ and $2.9 \%$ of infants $[52,61-63]$.

\section{Spinal Cord and Skeletal Anomalies (Including Arthrogryposis)}

The spectrum of neurological abnormalities in CZS also includes spinal cord injuries. Immunohistochemistry showed immunoreactivity for the ZIKV proteins in the gray matter of the spinal cord [64]. Needle electromyography showed moderate signs of remodeling of the motor units (polyphasic motor unit potentials with increased amplitude and duration) and a reduced recruitment pattern, suggesting chronic involvement of peripheral motor neurons [65].

The spinal cord is also abnormally shaped because of small corticospinal tracts, in addition to motor neuron degeneration and loss. Gliosis, small, or coarse foci of calcifications have also been described [45].

Reduction in the thickness of spinal cord segments is present in $83 \%$ of patients with CZS. The thoracic segment is the most often compromised, encompassing the totality of these infants with thinned spinal cords. Additional findings include a reduction of the anterior nerve roots of the conus medullaris. Moreover, there are reports of congenital hip dysplasia, more frequent among infants with arthrogryposis. In addition, half of these infants with arthrogryposis had a prominent anterior median fissure of the spinal cord, a feature not identified in any of the children without arthrogryposis [66]. Clubfoot and arthrogryposis were reported each one in $10.4 \%$ of newborns with CZS [67].

\section{Ocular Abnormalities}

Ocular features of CZS are mainly characterized by macular pigment mottling, neuroretinal atrophy with macular involvement, iris coloboma, and changes in the retinal vasculature [68]. Eye abnormalities were described in about $44 \%$ of infants with CZS. The most frequent findings were the following: macular lesions (pigmentary maculopathy, pigment mottling, lacunar maculopathy, or macular chorioretinal atrophy with and without hyperpigmented borders), present in all patients with ocular lesions; followed by optic nerve abnormalities $(55 \%)$; chorioretinal atrophy/scarring (21\%); and focal pigment mottling of the retina $(14 \%)$ [43•]. Microphthalmia occurs in only $4.2 \%$ of patients [69].

\section{Neuroimaging Findings in Children with Congenital ZIKV Infection Without Microcephaly}

The main neuroimaging findings in children with CZS without microcephaly include malformations of cortical development (predominantly affecting the anterior part of the brain); calcifications, usually at the corticomedullary junction, decreased brain volume, and ventriculomegaly. Hypoplasia of the corpus callosum, cerebellum, and brainstem, as well as delayed myelination, was also reported [34]. Cranial nerve enhancement and cerebral infarction may be among the expanding list of neurological findings in congenital ZIKV infection in normocephalic newborns with intrauterine virus exposure [70]. It suggests that there may be a wide spectrum of findings associated with CZS and that the microcephaly may be the most severe end of this spectrum [71].

\section{Neuroimaging Findings of Acquired Zika Virus Infection}

Neuroimaging findings of postnatally acquired ZIKV infection include a heterogeneous spectrum of diseases affecting the brain, peripheral nerves, and spinal cord [72]. ZIKVrelated Guillain-Barré syndrome (GBS) presented as postcontrast enhancement of the conus medullaris and cauda equina nerve roots on spine MRI (most commonly seen in the anterior nerve roots). On brain MRI, the cranial nerves may show post-contrast enhancement, especially the facial (VII) and trigeminal (V) nerves [73].

ZIKV-related acute transverse myelitis (ATM) usually involves more than 3 spine segments in length [74]. The spectrum of meningoencephalitis, presented as asymmetric subcortical hyperintense lesions, was best seen on fluidsensitive pulse sequences, with cytotoxic edema and at times with foci of restricted diffusion $[75,76]$. Acute disseminated 
encephalomyelitis (ADEM) has also been described with multiple ill-defined, asymmetric lesions involving the subcortical and deep white matter and deep gray matter nuclei [77].

\section{Neuroimaging Techniques}

\section{Prenatal Ultrasonography}

Doppler ultrasonography during pregnancy can detect congenital abnormalities with low sensitivity, but higher specificity [78]. Brain abnormalities observed by ultrasonography in fetuses affected by ZIKV include abnormal head shape, declining head measurements on serial scans, cerebral atrophy, increased extra-axial fluid, micro-calcification, and cerebellar hypoplasia. Even if the first evaluation is normal, it is necessary to follow up potentially affected fetuses throughout the pregnancy because abnormalities might not be apparent until the third trimester [79].

Among 92 fetuses from pregnant women diagnosed during pregnancy with ZIKV infection, eleven (12\%) had ZIKVassociated abnormal findings, comprising (1) major CNS abnormalities ( $11 \%$ of fetuses) characterized by microcephaly $(8 \%)$, calcifications $(10 \%)$, ventriculomegaly $(7 \%)$, Blake pouch cyst (3\%), cerebellar vermis hypoplasia (3\%), agenesis of the corpus callosum (2\%); (2) fetal growth restriction (8\%); and (3) arthrogryposis (1\%). Postnatal neuroimaging was performed in 68 neonates, of whom $23(34 \%)$ had abnormal results [80].

\section{Prenatal MR Imaging}

Fetal magnetic resonance imaging (F-MRI) may be useful to diagnose cortical development disorders compared with ultrasound [57]. F-MRI can also better describe than prenatal ultrasonography the following abnormalities: corpus callosum dysgenesis (hypogenesis, agenesis, hypoplasia), myelination status according to the stage of development (normal or delayed), and cerebral ventricular enlargement due to white matter hypoplasia (mainly affecting the posterior aspect of the lateral ventricles) [81].

Malformations of cortical development in CZS are described as polymicrogyria, schizencephaly, and lissencephaly-pachygyria spectrum, but F-MRI usually is not able to distinguish among these findings. F-MRI may improve the identification of brain malformations such as cerebral atrophy and microphthalmia. A frequent and typical finding at F-MRI is redundant scalp skin in the occipital region, which may also be seen at postnatal imaging or even during physical examination of the newborn [26]. Conversely, when compared with ultrasound, prenatal MRI is less sensitive in the detection of parenchymal calcifications [82].

\section{Postnatal Transfontanellar Ultrasonography}

Postnatal transfontanellar ultrasonography is the examination of choice for the assessment of newborns. It is an inexpensive and safe modality for the first-line investigation of suspected neonates. Both brain parenchyma and the ventricular system can be evaluated by ultrasound [83], although the fontanelles may be closed due to a collapse of the upper cranial bones $[9$, 84].

Postnatal transfontanellar neurosonography showed ventriculomegaly in $28 \%$ of newborns. Cerebral calcifications were detected in $34.9 \%$ of newborns; neuronal migrational abnormalities were present in $31.1 \%$; dysgenesis of the corpus callosum in 26\%; cerebellar atrophy and dilatation of the 4th ventricle in $16.2 \%$ and $17.3 \%$ of cases, respectively [85].

\section{Postnatal Computed Tomography}

The main findings in brain computed tomography (CT) are calcifications (predominantly at the cortico-subcortical junction, in the frontal lobes), malformation of cortical development, cerebral volume reduction, and ventriculomegaly and prominence of the occipital bone [47].

$\mathrm{CT}$ is the best imaging modality for the identification and delineation of calcifications [86]. Compared with prenatal ultrasound, CT was able to detect cerebellar vermis hypoplasia and corpus callosum dysgenesis that was undetected at the prenatal scan [87].

Head CT scans with 3D reconstructions are useful to demonstrate craniofacial disproportion with depression of the frontal and parietal bones, overlapping sutures, cranial bone collapse, and prominent appearance of the occipital and frontal regions. Small fontanels may be best seen on the bone window $[58 \bullet \bullet$.

\section{Postnatal Magnetic Resonance Imaging}

Malformations of cortical development and sulcation are common imaging findings in ZIKV-infected children and are best assessed with postnatal MR imaging [88]. Delayed myelination and demyelination are observed in some cases and may be associated with secondary thinning of the corpus callosum, events better depicted by MR imaging [9].

Although MRI is less sensitive than CT for calcifications, in this study, most of the calcifications were identified on T1weighted or susceptibility-weighted imaging [61••]. MRI is also useful to detect brainstem and cerebellar abnormalities [57].

Other features of CZS better visualized by postnatal MRI include intraventricular septations, gray matter heterotopia, and schizencephaly [56॰]. In addition, MRI is able to better visualize polymicrogyria, most 
frequently seen in the frontal lobes [87]. MRI also allows superior visualization of brainstem hypoplasia, cerebellar hemispheric volume loss, and other described abnormalities such as pseudocysts [89]. Table 1 summarizes the spectrum of brain and systemic abnormalities in $\mathrm{CZS}$.

\section{Differential Diagnosis}

The main differential diagnoses of CZS include congenital infections such as toxoplasmosis, rubeola, cytomegalovirus, and herpes simplex (TORCH); and heritable disorders like Aicardi-Goutières syndrome, band-like
Table 1 Main neurological findings on CZS $[32,43,47$, $51-54,58-62,66,68,72]$

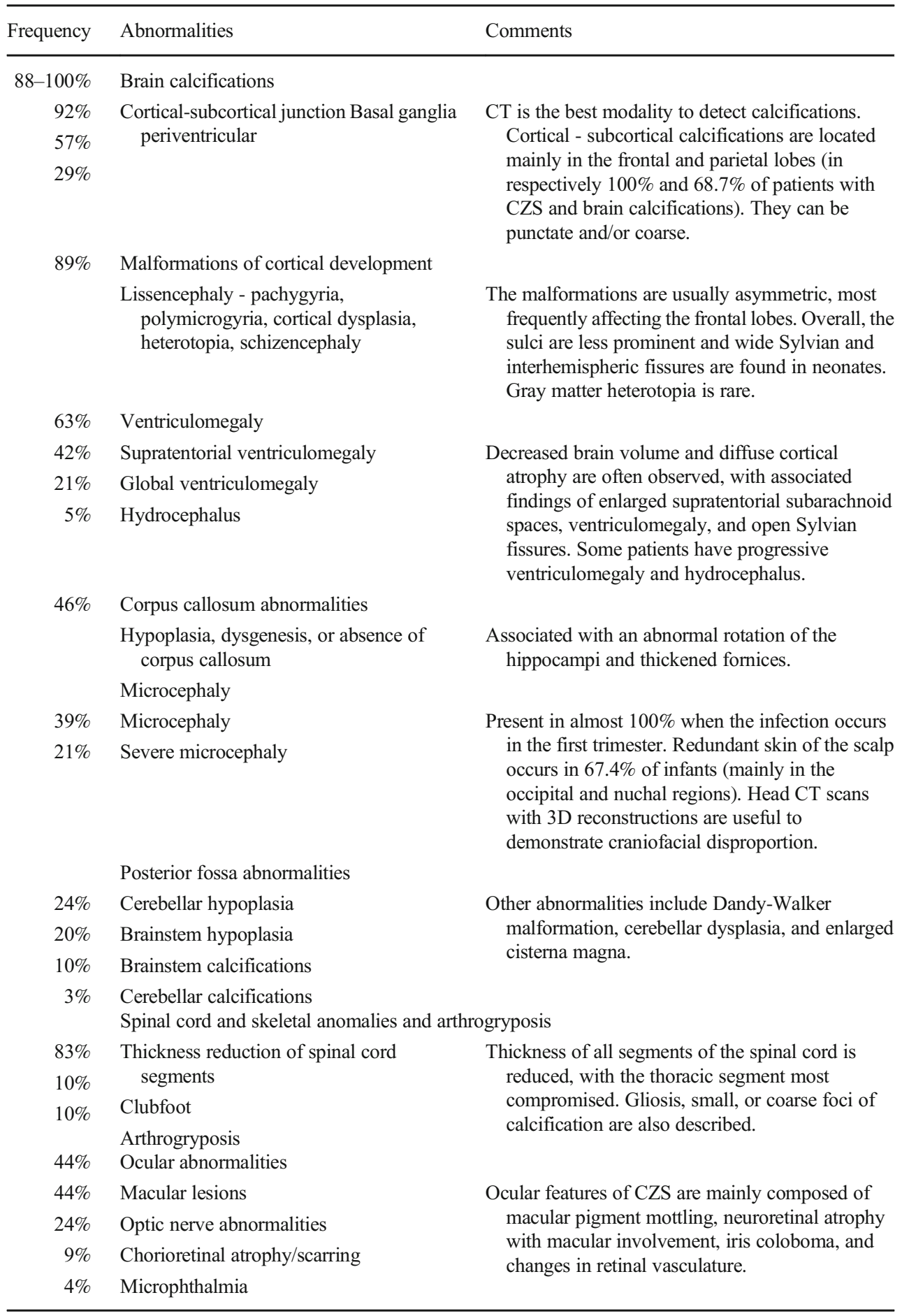

Abbreviations: $C T$, computed tomography; $C Z S$, congenital Zika syndrome; $3 D$, three-dimensional 
cerebral calcifications associated with pathogenic sequence variations in $O C L N$ (a.k.a. "pseudo-TORCH syndrome," and RNASET2-related leukodystrophy, that may manifest with findings similar to those of congenital ZIKV infection [86].

\section{Treatment and Prevention Perspectives}

Current treatment protocols for ZIKV infection mostly involve symptomatic care and rehabilitation. At present, there are no specific ZIKV vaccines or therapies available [90]. Antivirals used for the treatment of hepatitis C virus, including sofosbuvir and other antiviral agents such as favipiravir, have been used for potential treatment of ZIKV infection in animal models [91]. The antimalarial drug chloroquine inhibits ZIKV infection limiting vertical transmission of ZIKV infection and fetal growth defects when used in pregnant mice [92]. Several candidate ZIKV vaccines are currently under development, being already on phase 1 clinical trials [93]. Surgical interventions, such as ventriculoperitoneal shunt procedure, are indicated for children with progressive ventricular enlargement due to hydrocephalus $[59,60]$.

\section{Conclusions}

The heterogeneous spectrum of abnormalities in CZS is characterized by multisystem involvement. Main brain features observed are parenchymal calcifications, malformations of cortical development, callosal abnormalities, and brainstem and cerebellar abnormalities.

Imaging techniques such as ultrasound, MRI, or CT may be performed in the prenatal and/or in the postnatal periods. More studies will be required to further understand the entire spectrum of the brain abnormalities, including new techniques in radiology and nuclear medicine, in addition to new molecular studies to explore better the complexity of ZIKV infection.

\section{Compliance with Ethical Standards}

Conflict of Interest Leão VHP, Aragão MM, Pinho RS, Hazin AN, Paciorkowski AR, Penalva de Oliveira AC, and Masruha, MR each declare no potential conflicts of interest.

Human and Animal Rights and Informed Consent This article does not contain any studies with human or animal subjects performed by any of the authors.

\section{References}

Papers of particular interest, published recently, have been highlighted as:

- Of importance

- Of major importance

1. Campos GS, Bandeira AC, Sardi SI. Zika virus outbreak, Bahia, Brazil. Emerg Infect Dis. 2015;21(10):1885-6.

2. Newman C, Friedrich TC, O'Connor DH. Macaque monkeys in Zika virus research: 1947-present. Curr Opin Virol. 2017;25:34 40.

3. Christofferson RC. Zika virus emergence and expansion: lessons learned from dengue and chikungunya may not provide all the answers. Am J Trop Med Hyg. 2016;95(1):15-8.

4. Musso D, Gubler DJ. Zika virus. Clin Microbiol Rev. 2016;29(3): 487-524.

5. Hussain A, Ali F, Latiwesh OB, Hussain S. A comprehensive review of the manifestations and pathogenesis of Zika virus in neonates and adults. Cureus. 2018;10(9):e3290.

6. Petersen LR, Jamieson DJ, Powers AM, Honein MA. Zika Virus. N Engl J Med. 2016;374(16):1552-63.

7. Sejvar JJ. Zika virus and other emerging arboviral central nervous system infections. Continuum (Minneap Minn). 2018;24(5, Neuroinfectious Disease):1512-34.

8. Reid S, Rimmer K, Thakur K. Zika virus and neurologic disease. Neurol Clin. 2018;36(4):767-87.

9. Moore CA, Staples JE, Dobyns WB, Pessoa A, Ventura CV, Fonseca EB, et al. Characterizing the pattern of anomalies in congenital Zika syndrome for pediatric clinicians. JAMA Pediatr. 2017;171(3):288-95.

10. Franca GV, Schuler-Faccini L, Oliveira WK, Henriques CM, Carmo EH, Pedi VD, et al. Congenital Zika virus syndrome in Brazil: a case series of the first 1501 livebirths with complete investigation. Lancet. 2016;388(10047):891-7.

11. Yuan L, Huang XY, Liu ZY, Zhang F, Zhu XL, Yu JY, et al. A single mutation in the prM protein of Zika virus contributes to fetal microcephaly. Science. 2017;358(6365):933-6.

12. Priyamvada L, Quicke KM, Hudson WH, Onlamoon N, Sewatanon $\mathrm{J}$, Edupuganti S, et al. Human antibody responses after dengue virus infection are highly cross-reactive to Zika virus. Proc Natl Acad Sci U S A. 2016;113(28):7852-7.

13. Dejnirattisai W, Supasa P, Wongwiwat W, Rouvinski A, BarbaSpaeth G, Duangchinda T, et al. Dengue virus sero-crossreactivity drives antibody-dependent enhancement of infection with zika virus. Nat Immunol. 2016;17(9):1102-8.

14. Gaburro J, Bhatti A, Harper J, Jeanne I, Dearnley M, Green D, et al. Neurotropism and behavioral changes associated with Zika infection in the vector Aedes aegypti. Emerg Microbes Infect. 2018;7(1): 68.

15. World Health Organization. Emergencies: Zika situation report World Health Organization website 2017 [cited 2017 March 10]. Available from: http:/www.who.int/emergencies/zika-virus/ situation-report/10-march-2017/en/.

16. O'Reilly KM, Lowe R, Edmunds WJ, Mayaud P, Kucharski A, Eggo RM, et al. Projecting the end of the Zika virus epidemic in Latin America: a modelling analysis. BMC Med. 2018;16(1):180.

17. Yan Y, Zhang XT, Wang G, Cheng X, Yan Y, Fu YJ, et al. Zika virus induces abnormal cranial osteogenesis by negatively affecting cranial neural crest development. Infect Genet Evol. 2019;69:17689.

18. Kuszpit K, Hollidge BS, Zeng X, Stafford RG, Daye S, Zhang X, et al. [(18)F]DPA-714 PET imaging reveals global 
neuroinflammation in Zika virus-infected mice. Mol Imaging Biol. 2018;20(2):275-83.

19. Chimelli L, Avvad-Portari E. Congenital Zika virus infection: a neuropathological review. Childs Nerv Syst. 2018;34(1):95-9.

20. Driggers RW, Ho CY, Korhonen EM, Kuivanen S, Jaaskelainen AJ, Smura T, et al. Zika virus infection with prolonged maternal viremia and fetal brain abnormalities. N Engl J Med. 2016;374(22): 2142-51.

21. Chimelli L, Moura Pone S, Avvad-Portari E, Farias Meira Vasconcelos Z, Araujo Zin A, Prado Cunha D, et al. Persistence of Zika virus after birth: clinical, virological, neuroimaging, and neuropathological documentation in a 5-month infant with congenital Zika syndrome. J Neuropathol Exp Neurol 2018;77(3):193198.

22. Siqueira Mello A, Pascalicchio Bertozzi APA, Rodrigues MMD, Gazeta RE, Moron AF, Soriano-Arandes A, et al. Development of secondary microcephaly after delivery: possible consequence of mother-baby transmission of Zika virus in breast milk. Am J Case Rep. 2019;20:723-5.

23. Vianna RAO, Lovero KL, Oliveira SA, Fernandes AR, Santos T, Lima $\mathrm{L}$, et al. Children born to mothers with rash during Zika virus epidemic in Brazil: first 18 months of life. J Trop Pediatr. 2019;65: 592-602.

24. Li H, Saucedo-Cuevas L, Regla-Nava JA, Chai G, Sheets N, Tang W, et al. Zika virus infects neural progenitors in the adult mouse brain and alters proliferation. Cell Stem Cell. 2016;19(5):593-8.

25. Rawal G, Yadav S, Kumar R. Zika virus: an overview. J Family Med Prim Care. 2016;5(3):523-7.

26. Ribeiro BG, Werner H, Lopes F, Hygino da Cruz LC Jr, Fazecas TM, Daltro PAN, et al. Central nervous system effects of intrauterine Zika virus infection: a pictorial review. Radiographics. 2017;37(6):1840-50.

27. Landais A, Cesaire A, Fernandez M, Breurec S, Herrmann C, Delion F, et al. ZIKA vasculitis: a new cause of stroke in children? J Neurol Sci. 2017;383:211-3.

28. Baud D, Gubler DJ, Schaub B, Lanteri MC, Musso D. An update on Zika virus infection. Lancet. 2017;390(10107):2099-109.

29. Moura da Silva AA, Ganz JS, Sousa PD, Doriqui MJ, Ribeiro MR, Branco MD, et al. Early growth and neurologic outcomes of infants with probable congenital Zika virus syndrome. Emerg Infect Dis. 2016;22(11):1953-6 The authors describe the follow-up and the clinical outcomes after 8 months of infants with CZS.

30. Hagglund G, Wagner P. Development of spasticity with age in a total population of children with cerebral palsy. BMC Musculoskelet Disord. 2008;9:150.

31. Pessoa A, van der Linden V, Yeargin-Allsopp M, Carvalho M, Ribeiro EM, Van Naarden BK, et al. Motor abnormalities and epilepsy in infants and children with evidence of congenital Zika virus infection. Pediatrics. 2018;141(Suppl 2):S167-S79.

32. Del Campo M, Feitosa IM, Ribeiro EM, Horovitz DD, Pessoa AL, Franca GV, et al. The phenotypic spectrum of congenital Zika syndrome. Am J Med Genet A. 2017;173(4):841-57.

33. van der Linden H, Jr., Carvalho MD, van der Linden V, Lacerda KM, Pessoa A, Carneiro ML, et al. Epilepsy profile in infants with congenital Zika virus infection. N Engl J Med. 2018;379(9):891-2.

34. van der Linden V, Pessoa A, Dobyns W, Barkovich AJ, Junior HV, Filho EL, et al. Description of 13 infants born during October 2015January 2016 with congenital Zika virus infection without microcephaly at birth - Brazil. MMWR Morb Mortal Wkly Rep. 2016;65(47):1343-8.

35. Walker CL, Little ME, Roby JA, Armistead B, Gale M Jr, Rajagopal L, et al. Zika virus and the nonmicrocephalic fetus: why we should still worry. Am J Obstet Gynecol. 2019;220(1): $45-56$.

36. Adams Waldorf KM, Nelson BR, Stencel-Baerenwald JE, Studholme C, Kapur RP, Armistead B, et al. Congenital Zika virus infection as a silent pathology with loss of neurogenic output in the fetal brain. Nat Med. 2018;24(3):368-74.

37. Boldrini M, Fulmore CA, Tartt AN, Simeon LR, Pavlova I, Poposka V, et al. Human hippocampal neurogenesis persists throughout aging. Cell Stem Cell. 2018;22(4):589-99 e5.

38. Toda T, Parylak SL, Linker SB, Gage FH. The role of adult hippocampal neurogenesis in brain health and disease. Mol Psychiatry. 2019;24(1):67-87.

39. Kalkbrenner AE, Daniels JL, Chen JC, Poole C, Emch M, Morrissey J. Perinatal exposure to hazardous air pollutants and autism spectrum disorders at age 8. Epidemiology. 2010;21(5): $631-41$.

40. Centers for Disease Control and Prevention. Update: interim guidance for health care providers caring for pregnant women with possible Zika virus exposure - United States (including U.S. territories) centers for disease control and prevention website2017 [cited 2017 August 9th]. Available from: https://www.cdc.gov/ pregnancy/zika/testing-follow-up/testing-and-diagnosis.html.

41. Pomar L, Musso D, Malinger G, Vouga M, Panchaud A, Baud D. Zika virus during pregnancy: from maternal exposure to congenital Zika virus syndrome. Prenat Diagn. 2019;39(6):420-30.

42. Vorona GA, Lanni SM. Fetal magnetic resonance imaging evaluation of a 21-week fetus with Zika virus infection. Pediatr Neurol. 2016;65:98-9.

43. Marques VM, Santos CS, Santiago IG, Marques SM, Nunes Brasil MDG, Lima TT, et al. Neurological Complications of Congenital Zika Virus Infection. Pediatr Neurol. 2019;91:3-10 It is a review about neurological and ophthalmological findings in CZS based on 34 papers on the literature.

44. Ribeiro BNF, Muniz BC, Gasparetto EL, Ventura N, Marchiori E. Congenital Zika syndrome and neuroimaging findings: what do we know so far? Radiol Bras. 2017;50(5):314-22.

45. Chimelli L, Melo ASO, Avvad-Portari E, Wiley CA, Camacho AHS, Lopes VS, et al. The spectrum of neuropathological changes associated with congenital Zika virus infection. Acta Neuropathol. 2017;133(6):983-99.

46. Soares de Oliveira-Szejnfeld P, Levine D, Melo AS, Amorim MM, Batista AG, Chimelli L, et al. Congenital brain abnormalities and Zika virus: what the radiologist can expect to see prenatally and postnatally. Radiology. 2016;281(1):203-18 This article was performed with 35 infants with diagnosis of confirmed and presumed CZS associated with brain abnormalities.

47. Petribu NCL, Fernandes ACV, Abath MB, Araujo LC, de Queiroz FRS, Araujo JM, et al. Common findings on head computed tomography in neonates with confirmed congenital Zika syndrome. Radiol Bras. 2018;51(6):366-71.

48. de Souza AS, de Oliveira-Szjenfeld PS, de Oliveira Melo AS, de Souza LAM, Batista AGM, Tovar-Moll F. Imaging findings in congenital Zika virus infection syndrome: an update. Childs Nerv Syst. 2018;34(1):85-93 This is a review of literature based on TC, MRI, and ultrasound imaging performed prenatal and postnatal stages.

49. Tarrant A, Garel C, Germanaud D, de Villemeur TB, Mignot C, Lenoir M, et al. Microcephaly: a radiological review. Pediatr Radiol. 2009;39(8):772-80 quiz 888-9.

50. Kalmin MM, Gower EW, Stringer EM, Bowman NM, Rogawski McQuade ET, Westreich D. Misclassification in defining and diagnosing microcephaly. Paediatr Perinat Epidemiol. 2019;33(4):28690.

51. Ashwal S, Michelson D, Plawner L, Dobyns WB. Practice parameter: evaluation of the child with microcephaly (an evidence-based review): report of the quality standards Subcommittee of the American Academy of Neurology and the Practice Committee of the Child Neurology Society. Neurology. 2009;73(11):887-97.

52.• ML CL, Carvalho AL, Ventura PA, Taguchi TB, Fernandes AS, Pinho SF, et al. Clinical, neuroimaging, and neurophysiological 
findings in children with microcephaly related to congenital Zika virus infection. Int J Environ Res Public Health. 2019;16(3) This is a retrospective study of 102 newborns with microcephaly diagnosed at birth and gestational ZIKV clinical symptoms.

53. Kempermann G, Gage FH, Aigner L, Song H, Curtis MA, Thuret S, et al. Human adult neurogenesis: evidence and remaining questions. Cell Stem Cell. 2018;23(1):25-30.

54. Peixoto Filho AAA, de Freitas SB, Ciosaki MM, Oliveira LNE, Dos Santos Junior OT. Computed tomography and magnetic resonance imaging findings in infants with microcephaly potentially related to congenital Zika virus infection. Radiol Bras. 2018;51(2):119-22.

55. Barkovich AJ, Raybaud C. Pediatric neuroimaging. 6th ed: Lippincott Williams \& Wilkins; 2018.

56. Zare Mehrjardi M, Keshavarz E, Poretti A, Hazin AN. Neuroimaging findings of Zika virus infection: a review article. Jpn J Radiol. 2016;34(12):765-70 This article is a review of congenital and postnatally of neurological abnormalities related to CZS.

57. Guillemette-Artur P, Besnard M, Eyrolle-Guignot D, Jouannic JM, Garel C. Prenatal brain MRI of fetuses with Zika virus infection. Pediatr Radiol. 2016;46(7):1032-9.

58.• Mehrjardi MZ, Poretti A, Huisman TAGM, et al. Neuroimaging findings of congenital Zika virus infection: a pictorial essay. Jpn JRadiol. 2017;35:89-94 This review describes the neurological imaging findings of newborns with CZS, based on CT, MRI, and ultrasound imaging performed at prenatal and postnatal stages.

59. Jucá E, Pessoa A, Ribeiro E, Menezes R, Kerbage S, Lopes T, et al. Hydrocephalus associated to congenital Zika syndrome: does shunting improve clinical features? Childs Nerv Syst. 2017;34(1): $101-6$.

60. van der Linden V, de Lima Petribu NC, Pessoa A, Faquini I, Paciorkowski AR, van der Linden $\mathrm{H}$ Jr, et al. Association of severe hydrocephalus with congenital Zika syndrome. JAMA Neurol. 2019;76(2):203-10.

61.• de Fatima Vasco Aragao M, van der Linden V, Brainer-Lima AM, Coeli RR, Rocha MA, Sobral da Silva P, et al. Clinical features and neuroimaging (CT and MRI) findings in presumed Zika virus related congenital infection and microcephaly: retrospective case series study. BMJ. 2016;353:11901 The authors performed neuroimaging (MRI and CT) on 23 children with CZS and described the neurological findings associated with the syndrome.

62. Sanz Cortes M, Rivera AM, Yepez M, Guimaraes CV, Diaz Yunes I, Zarutskie A, et al. Clinical assessment and brain findings in a cohort of mothers, fetuses and infants infected with ZIKA virus. Am J Obstet Gynecol. 2018;218(4):440 e1-e36 This is a longitudinal cohort study of confirmed ZIKV infection in 12 pregnant women and evaluation of the outcomes of CZS on newborns.

63. Calvet G, Aguiar RS, Melo ASO, Sampaio SA, de Filippis I, Fabri $\mathrm{A}$, et al. Detection and sequencing of Zika virus from amniotic fluid of fetuses with microcephaly in Brazil: a case study. Lancet Infect Dis. 2016;16(6):653-60.

64. Ramalho FS, Yamamoto AY, da Silva LL, Figueiredo LTM, Rocha LB, Neder L, et al. Congenital Zika virus infection induces severe spinal cord injury. Clin Infect Dis. 2017;65(4):687-90.

65. van der Linden V, Filho EL, Lins OG, van der Linden A, Aragao Mde F, Brainer-Lima AM, et al. Congenital Zika syndrome with arthrogryposis: retrospective case series study. BMJ. 2016;354: i3899.

66. Aragao M, Brainer-Lima AM, Holanda AC, van der Linden V, Vasco Aragao L, Silva Junior MLM, et al. Spectrum of spinal cord, spinal root, and brain MRI abnormalities in congenital Zika syndrome with and without arthrogryposis. AJNR Am J Neuroradiol. 2017;38(5):1045-53.
67. Schuler-Faccini L, Ribeiro EM, Feitosa IM, Horovitz DD, Cavalcanti DP, Pessoa A, et al. Possible association between Zika virus infection and microcephaly - Brazil, 2015. MMWR Morb Mortal Wkly Rep. 2016;65(3):59-62.

68. Agrawal R, Oo HH, Balne PK, Ng L, Tong L, Leo YS. Zika virus and the eye. Ocul Immunol Inflamm. 2017;26(5):654-9.

69. de Oliveira Dias JR, Ventura CV, de Paula FB, Prazeres J, Ventura LO, Bravo-Filho V, et al. Zika and the eye: pieces of a puzzle. Prog Retin Eye Res. 2018;66:85-106.

70. Mulkey SB, Vezina G, Bulas DI, Khademian Z, Blask A, Kousa Y, et al. Neuroimaging findings in normocephalic newborns with intrauterine Zika virus exposure. Pediatr Neurol. 2018;78:75-8.

71. Aragao M, Holanda AC, Brainer-Lima AM, Petribu NCL, Castillo $\mathrm{M}$, van der Linden $\mathrm{V}$, et al. Nonmicrocephalic infants with congenital Zika syndrome suspected only after neuroimaging evaluation compared with those with microcephaly at birth and postnatally: how large is the Zika virus "iceberg"? AJNR Am J Neuroradiol. 2017;38(7):1427-34.

72. Zare Mehrjardi M, Carteaux G, Poretti A, Sanei Taheri M, Bermudez S, Werner $\mathrm{H}$, et al. Neuroimaging findings of postnatally acquired Zika virus infection: a pictorial essay. Jpn J Radiol. 2017;35(7):341-9.

73. Fontes CA, Dos Santos AA, Marchiori E. Magnetic resonance imaging findings in Guillain-Barre syndrome caused by Zika virus infection. Neuroradiology. 2016;58(8):837-8.

74. Mecharles S, Herrmann C, Poullain P, Tran TH, Deschamps N, Mathon $\mathrm{G}$, et al. Acute myelitis due to Zika virus infection. Lancet. 2016;387(10026): 1481.

75. Schwartzmann PV, Ramalho LN, Neder L, Vilar FC, AyubFerreira SM, Romeiro MF, et al. Zika virus meningoencephalitis in an immunocompromised patient. Mayo Clin Proc. 2017;92(3): $460-6$.

76. Soares CN, Brasil P, Carrera RM, Sequeira P, de Filippis AB, Borges VA, et al. Fatal encephalitis associated with Zika virus infection in an adult. J Clin Virol. 2016;83:63-5.

77. Niemeyer B, Niemeyer R, Borges R, Marchiori E. Acute disseminated encephalomyelitis following Zika virus infection. Eur Neurol. 2017;77(1-2):45-6.

78. Brasil P, Pereira JP Jr, Moreira ME, Ribeiro Nogueira RM, Damasceno L, Wakimoto M, et al. Zika virus infection in pregnant women in Rio de Janeiro. N Engl J Med. 2016;375(24):2321-34.

79. Sohan K, Cyrus CA. Ultrasonographic observations of the fetal brain in the first 100 pregnant women with Zika virus infection in Trinidad and Tobago. Int J Gynaecol Obstet. 2017;139(3):278-83.

80. Pereira JP Jr, Nielsen-Saines K, Sperling J, Maykin MM, Damasceno L, Cardozo RF, et al. Association of prenatal ultrasonographic findings with adverse neonatal outcomes among pregnant women with Zika virus infection in Brazil. JAMA Netw Open. 2018;1(8):e186529.

81. Araujo Junior E, Carvalho FH, Tonni G, Werner H. Prenatal imaging findings in fetal Zika virus infection. Curr Opin Obstet Gynecol. 2017;29(2):95-105.

82. Sanin-Blair JE, Gutierrez-Marquez C, Herrera DA, Vossough A. Fetal magnetic resonance imaging findings in prenatal Zika virus infection. Fetal Diagn Ther. 2017;42(2):153-7.

83. Pereira AM, Monteiro DLM, Werner H, Daltro P, Fazecas T, Guedes B, et al. Zika virus and pregnancy in Brazil: what happened? J Turk Ger Gynecol Assoc. 2018;19(1):39-47.

84. Dain Gandelman Horovitz D, da Silva Pone MV, Moura Pone S, Dias Saad Salles TR, Bastos Boechat MC. Cranial bone collapse in microcephalic infants prenatally exposed to Zika virus infection. Neurology. 2016;87(1):118-9.

85. Ximenes A, Pires P, Werner H, Jungmann PM, Rolim Filho EL, Andrade EP, et al. Neuroimaging findings using transfontanellar ultrasound in newborns with microcephaly: a possible association 
with congenital Zika virus infection. J Matern Fetal Neonatal Med. 2019;32(3):493-501.

86. Livingston JH, Stivaros S, Warren D, Crow YJ. Intracranial calcification in childhood: a review of aetiologies and recognizable phenotypes. Dev Med Child Neurol. 2014;56(7):612-26.

87. Pires P, Jungmann P, Galvao JM, Hazin A, Menezes L, Ximenes R, et al. Neuroimaging findings associated with congenital Zika virus syndrome: case series at the time of first epidemic outbreak in Pernambuco State. Brazil Childs Nerv Syst. 2018;34(5):957-63.

88. Hazin AN, Poretti A, Di Cavalcanti Souza Cruz D, Tenorio M, van der Linden A, Pena LJ, et al. Computed tomographic findings in microcephaly associated with Zika virus. N Engl J Med 2016;374(22):2193-2195.

89. Castro JDV, Pereira LP, Dias DA, Aguiar LB, Maia JCN, Costa J, et al. Presumed Zika virus-related congenital brain malformations: the spectrum of CT and MRI findings in fetuses and newborns. Arq Neuropsiquiatr. 2017;75(10):703-10.
90. Lowe R, Barcellos C, Brasil P, Cruz OG, Honorio NA, Kuper H, et al. The Zika virus epidemic in Brazil: from discovery to future implications. Int J Environ Res Public Health. 2018;15(1).

91. Ferreira AC, Zaverucha-do-Valle C, Reis PA, Barbosa-Lima G, Vieira YR, Mattos M, et al. Sofosbuvir protects Zika virusinfected mice from mortality, preventing short- and long-term sequelae. Sci Rep. 2017;7(1):9409.

92. Cao B, Parnell LA, Diamond MS, Mysorekar IU. Inhibition of autophagy limits vertical transmission of Zika virus in pregnant mice. J Exp Med. 2017;214(8):2303-13.

93. Gorshkov K, Shiryaev SA, Fertel S, Lin YW, Huang CT, Pinto A, et al. Zika virus: origins, pathological action, and treatment strategies. Front Microbiol. 2018;9:3252.

Publisher's Note Springer Nature remains neutral with regard to jurisdictional claims in published maps and institutional affiliations. 